Journal Of Al-Azhar University Engineering Sector

Vol. 14, No. 50, January, 2019, 422-433

\title{
GREEN ARCHITECTURE,ENERGY AND SUSTAINABILITY
}

\author{
Sameh Mohamed Hamed elyan \\ Thebes High Institute of Engineering
}

\begin{abstract}
Sustainable architecture or Green architecture is a general term that describes environmentally conscious design techniques in Architectural engineering field, it is a process of building design that respected the environment, taking into account minimize the energy consumption, such as materials and resource with reducing construction effects and the use of facilities on environment to conform to Nature Sustainable architecture seeks to minimize of negative environmental impact of building by enhanced efficiency in the use of materials and energy, so the idea of sustainability or environmental design is to insure that all life activities do not inhibit the future generations from the benefit of natural resources This energy considered in Egypt and the world is one of important issue which must be carefully studied it, because it plays a vital role in achieving the Sustainable development and related to all national economic sectors, the building sector is considered a part of sectors consuming total energy during construction and use In that sense, the energy conservation in architecture (Bio climatic architecture) or green architecture and how to design an architectural building that energysaving reach to thermal comfort, according to the nature of climatic regions depending on its location, climate, various activates represented in heating and cooling of the places and lighting and water heating and cooling, which is creating high energy consumption within building the goal of this search is calling for green architecture, which includes from its goals dealing with the surrounding environments of natural resources represented in usage of surrounding natural materials in construction from new and Renewable Energy such as ( Sun, wind, topography, air, water, water cliffs, sea waves, and land ) with reducing of traditional energy use and control in Architectural details Such as walls, roofs, landscaping, afforestation and the use of clean energy)
\end{abstract}

Key word : Architecture, Sustainability, energy

$$
\begin{aligned}
& \text { العمارة الخضر اءو والطاقة والاستدامة البيئية } \\
& \text { معهذ طيبة العالى للهندسة - أكاديمية طيبة بامدالمعادي }
\end{aligned}
$$

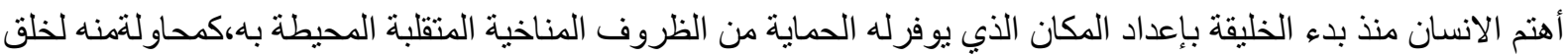

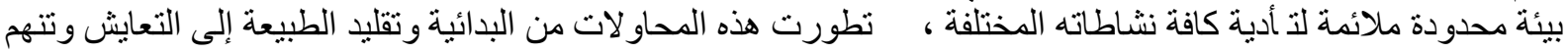

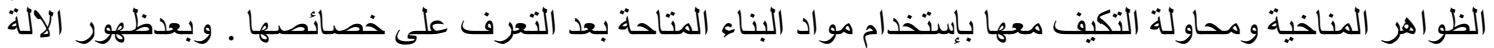

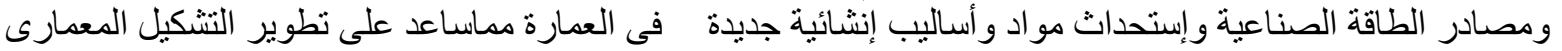

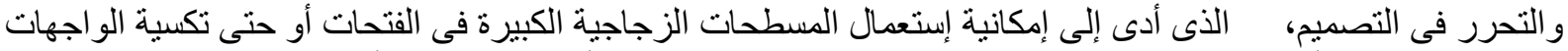

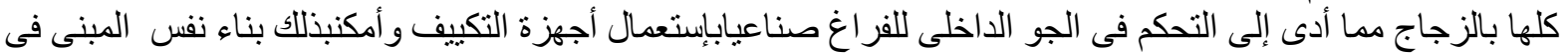

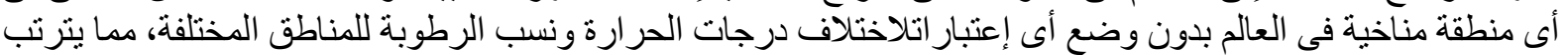

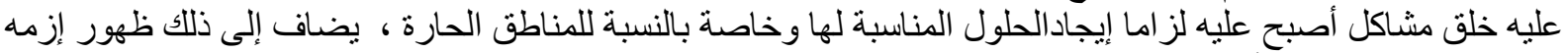

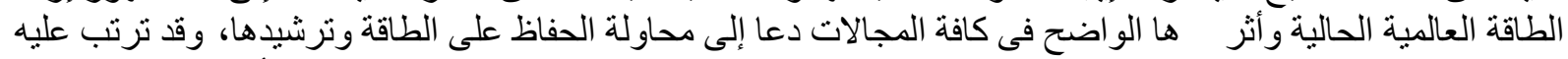

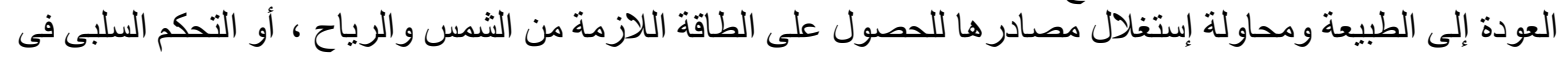


درجات الحرارة عن طريق الدر اسة العلمبة للعناصر المعمارية للمبنى حتى يتسنى تحقيق التصميم الانسب الذى يعمل على الإنى

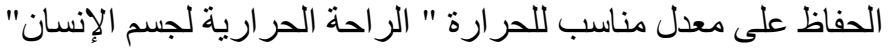

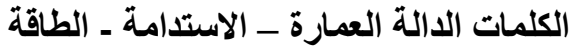

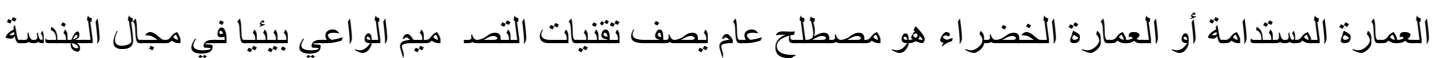
ملخص البحث البم العمات

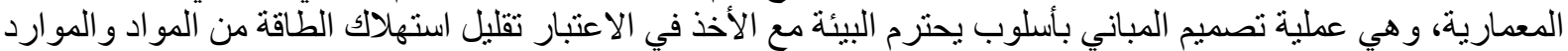

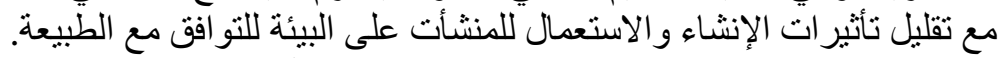

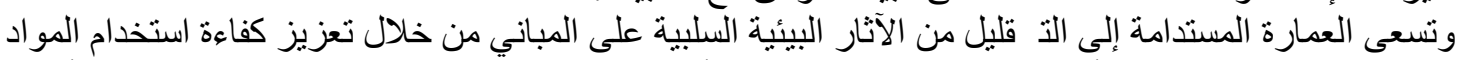

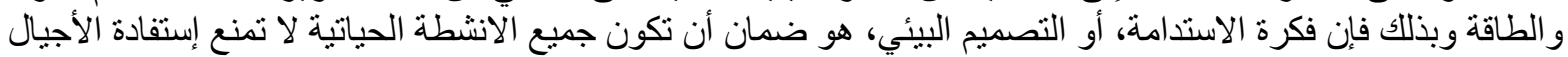

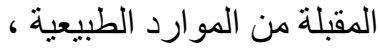

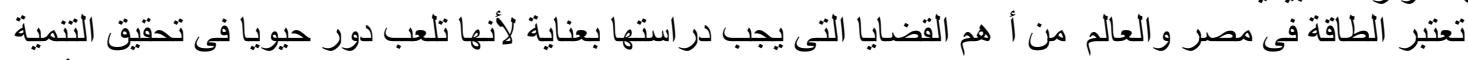
المستدامة و هى ترتبط بجميع قطاعات الاقتصاد القومى ويعتبر قطاع المبانى من القطاعات المستهلكة للطاقة الكلية أثناء

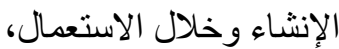

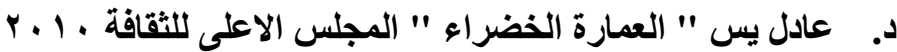

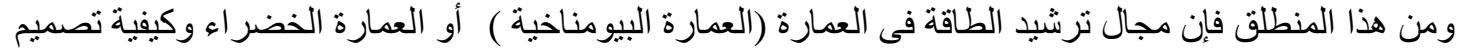

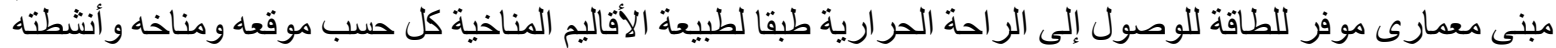

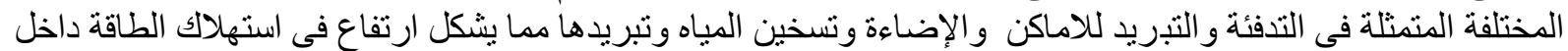

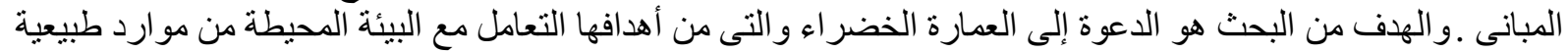

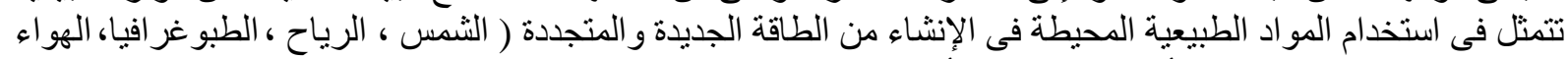

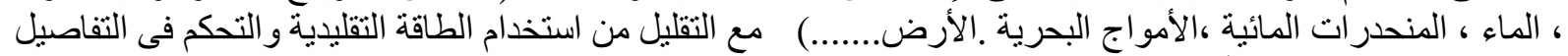

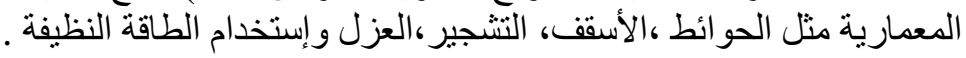

المشكلة البحثية

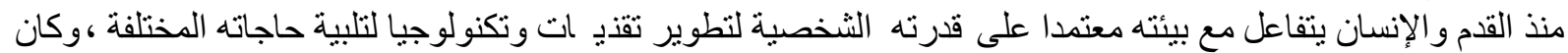

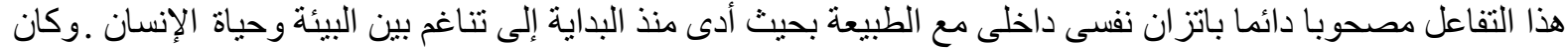

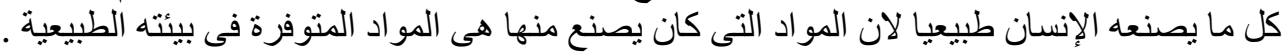

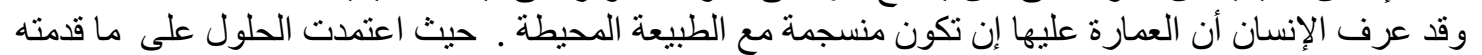

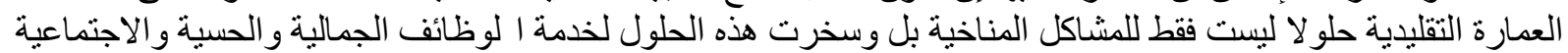
ونتيجة للثورة الصناعية وانتشار الصناعة بجوار العمران وتطور وسائل النقل وزيادة الانبعاثات الغازية والأدخنة مما أدى إلى : الط:

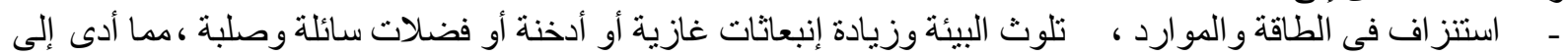

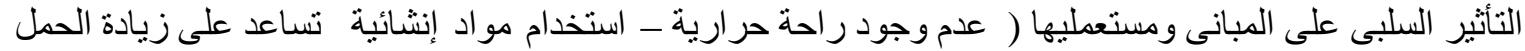

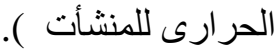
ـ ـ ـ ارتفاع تكلفة المعالجات التقليدية من الاستخدامات الصناعية( المكيفات ـ المر اوح) لتخفيف الحمل الحرارى، الإضاءة

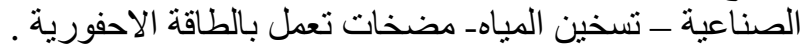

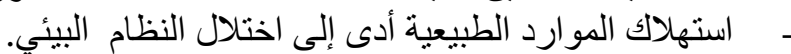

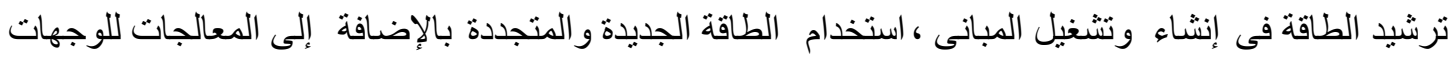
فرضية البحث:

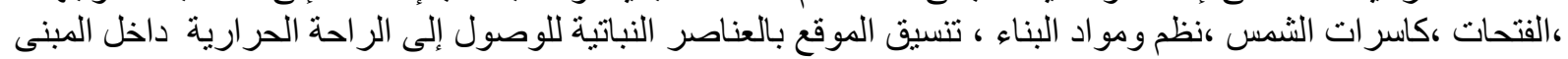

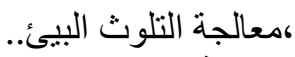
العمارة الخضر اء هى دعوة المهتمين بالبناء لإنتاج بيئة مشيدة حياتية ذات جودة عالية ويجب مر اعاة الاتى :

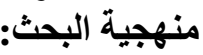

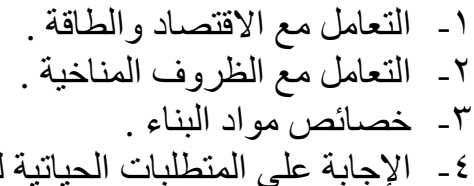

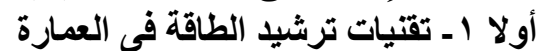

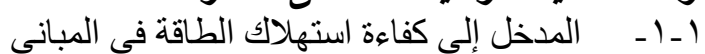

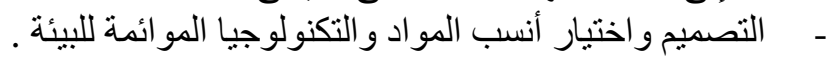


التحتية ،النظم التكنولوجية ، النظم الإدارية

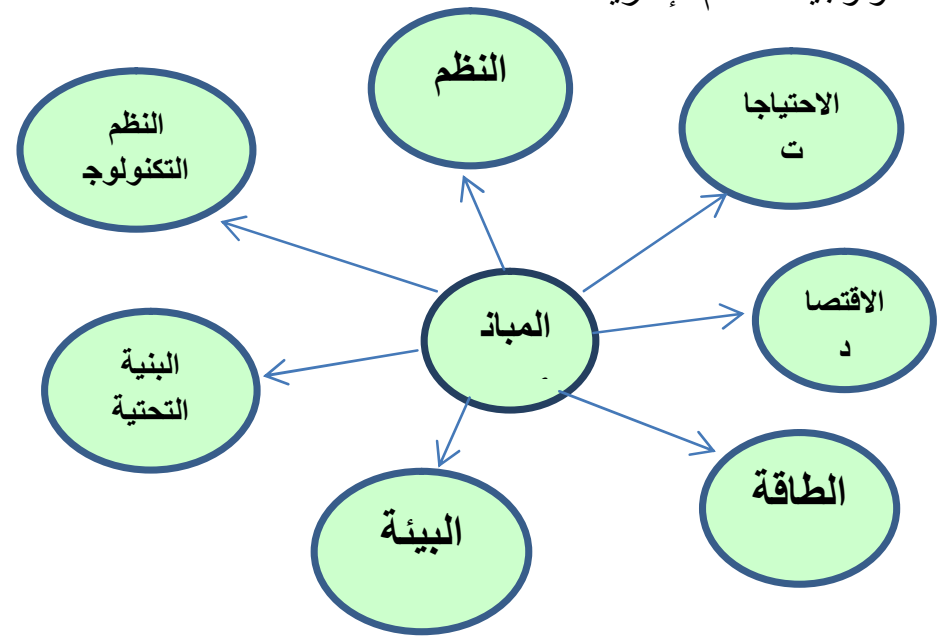

شكل رقم( ())العو امل المؤثرة على اختيار طرق ترشيد الطاقة فى المبانى

تقييم المبانى من ناحية الطاقة يتم تقسيم التقييم إلى حساب تكلفة للمر احل الآتية: الإنشائية، التشغيل و الصيانة، الإصلاح و الترميح.

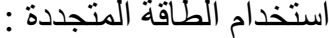
سخانات شمسية ، خلايا شمسية للإضاءة ، أنظمة الرياح لتوليد الكهرباء

\begin{tabular}{|c|c|c|}
\hline إمكانية الطاقة المتجددة & الطرق التقليدية & عناصر استهلاك الطاقة \\
\hline 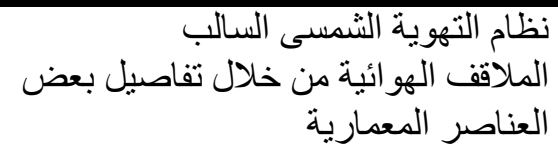 & المر اوح_المكيفات_المكيفات الصحر اوية & تبريد وتهوية المبانى \\
\hline نظام التسخين الثمسى السالب & الدكيفات ـــايات الكهربائية ـحرق الأخشاب & 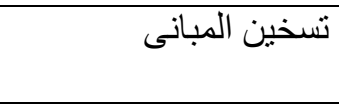 \\
\hline الإضاءة الطبيعية & الإضـاءة الكهربائية & الإضـاءة \\
\hline السخانات الشمسية & سخانات الكهرباء ـالغاز & تسخين المياه \\
\hline أنظمة الخلايا الثمسية، أنظمة الرياح & طلمبات كهربائية - ديزل -بنزين & تغذية وضخ المياة \\
\hline
\end{tabular}

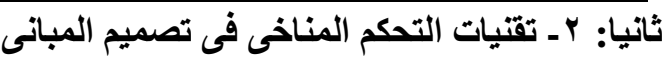

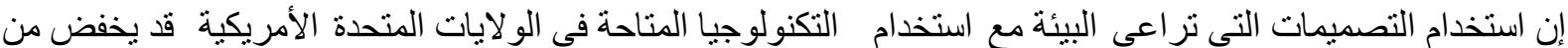

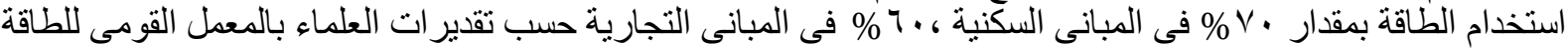

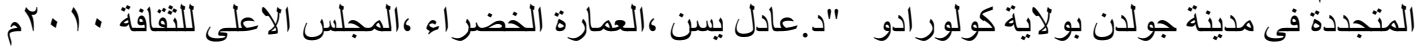

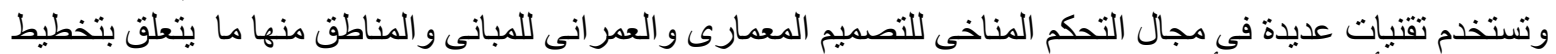

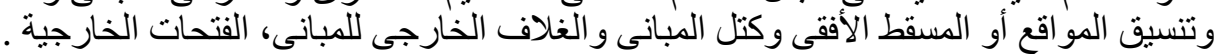

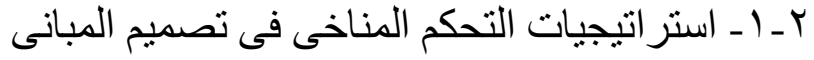

\begin{tabular}{|c|c|}
\hline صيفا & شتاء| \\
\hline 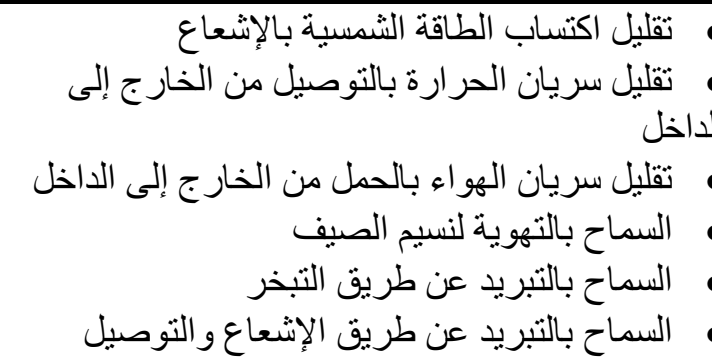 & 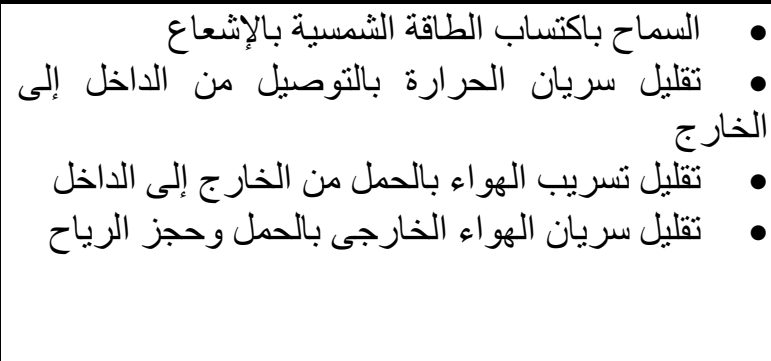 \\
\hline
\end{tabular}




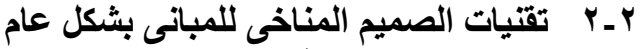

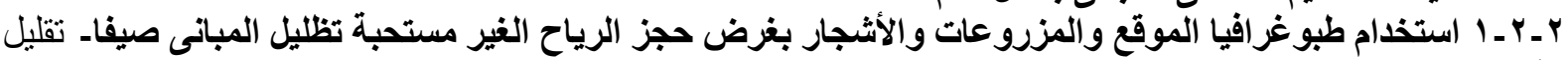

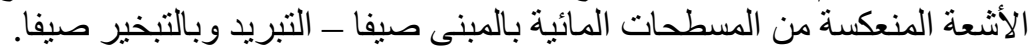

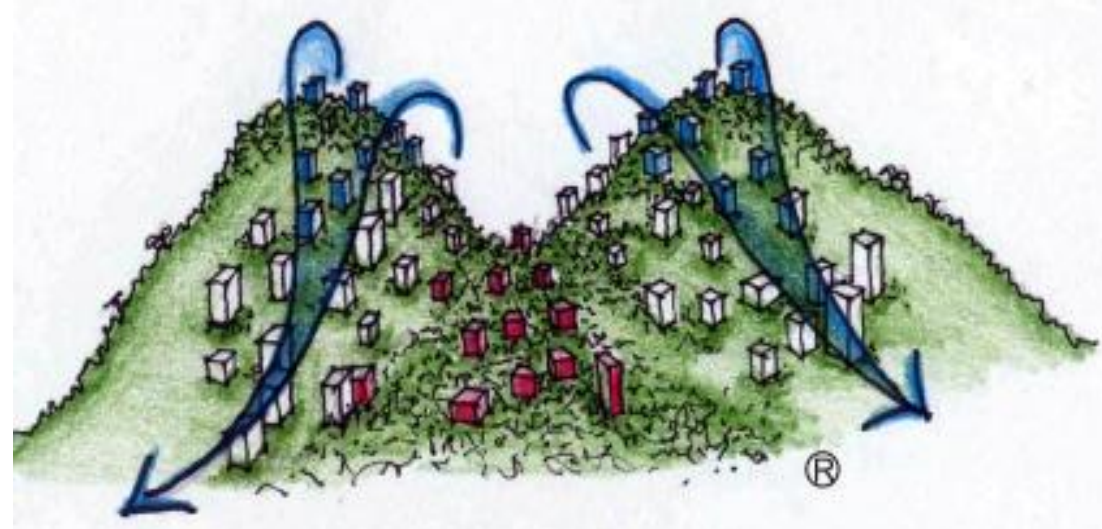

الثكل رقم (ץ) يوضح طبواغرفية الأرض والمزروعات وتأثيرها المناخى على التجمع السكنى

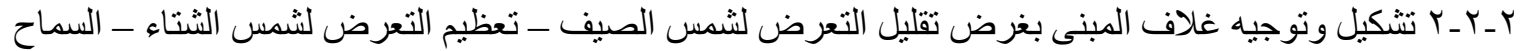

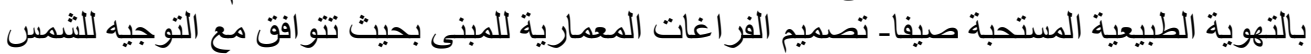

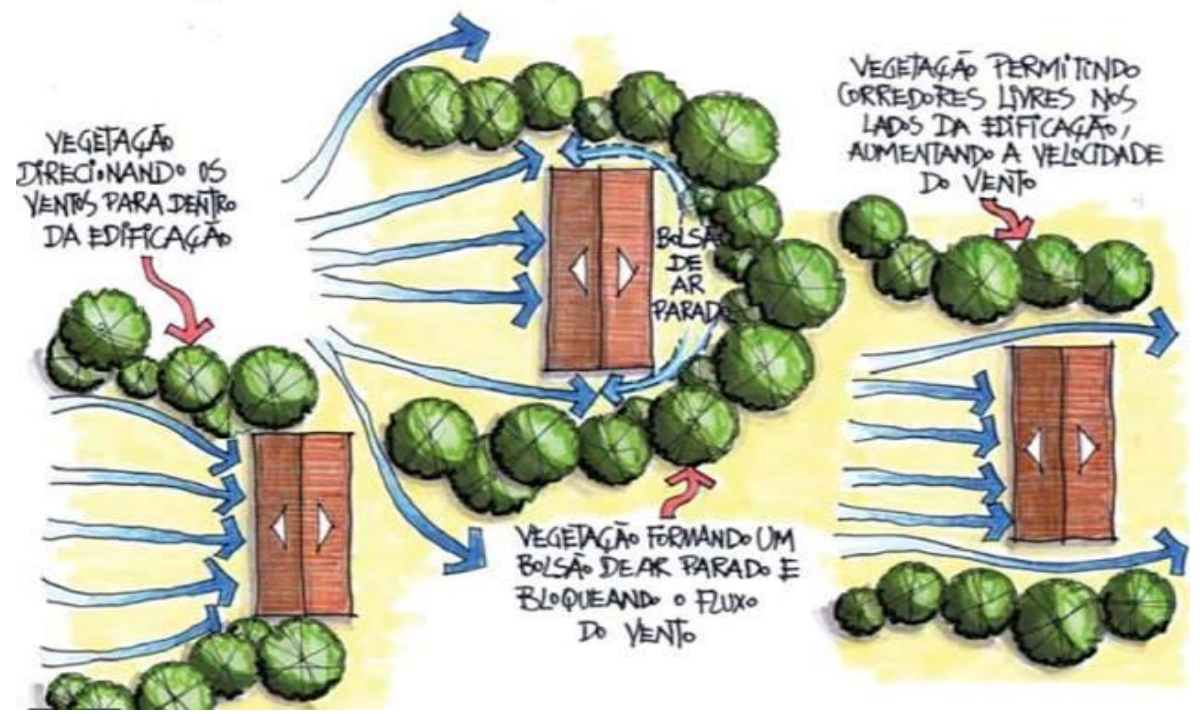

شكل رقم (r) تأثير تنسيق الموقع بالعناصر النباتية على حركة الرياح

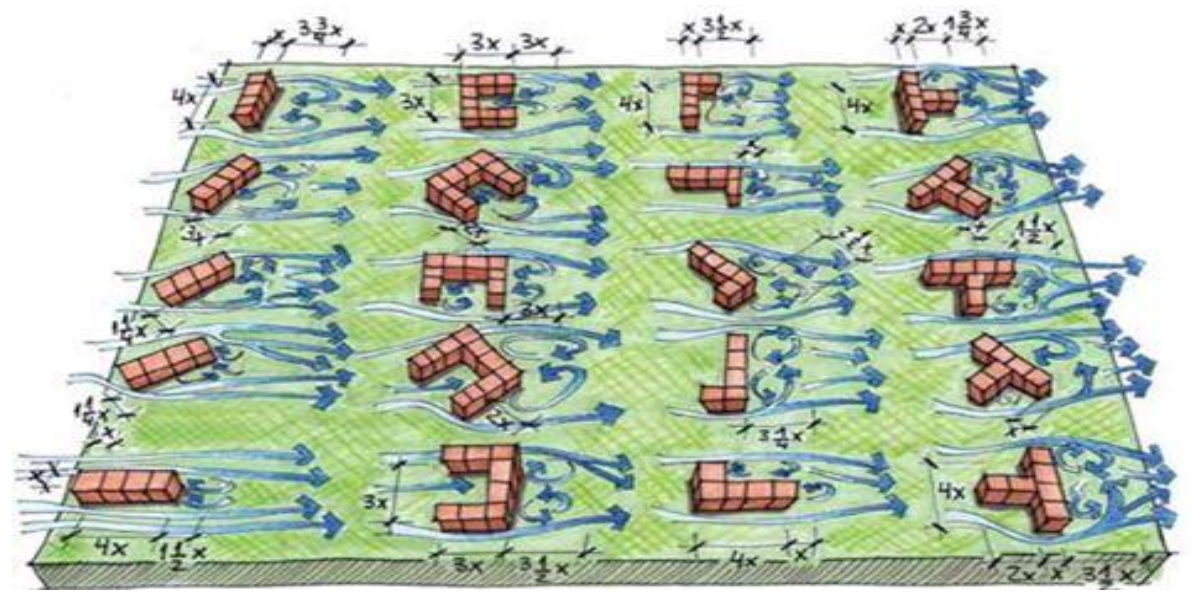

شكل رقم (ع ) توجيه المبانى وعلاقتها بحركة واتجاه الريح 


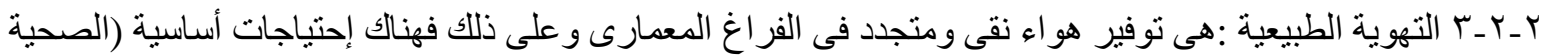

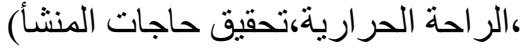
r

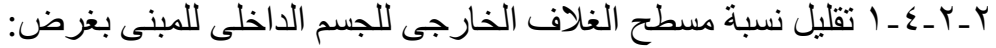

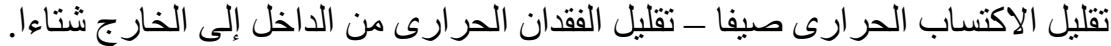

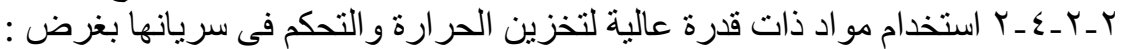

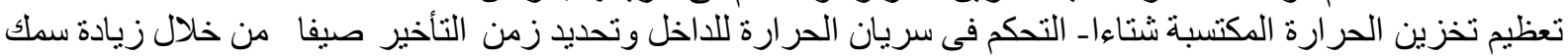
الحوائط، العزل، تقليل الفتحات الخارجية.

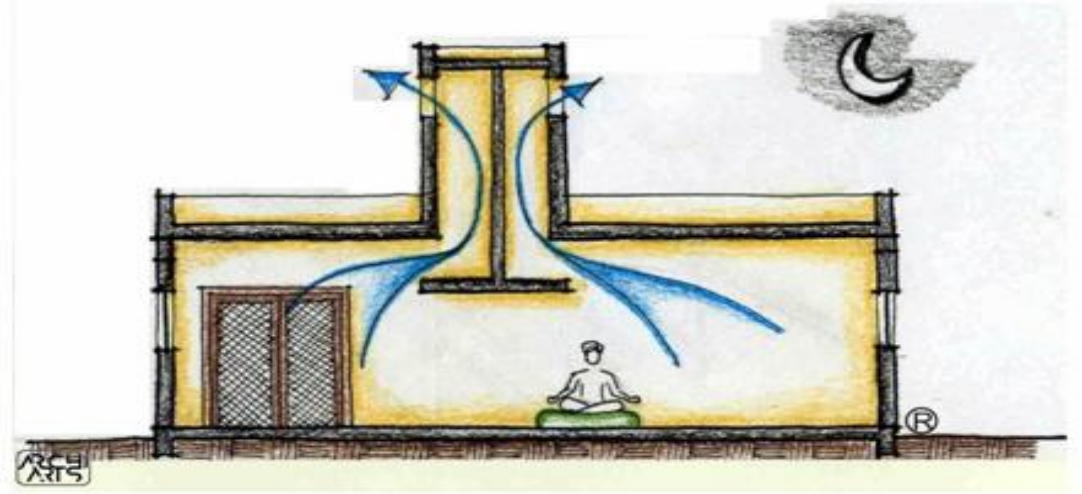

شكل رقم (ه) الشخشيخة أحدى العناصر المعمارية لاصطياد الهواء البارد والتخلص من الهواء الساخن داخل المبنى
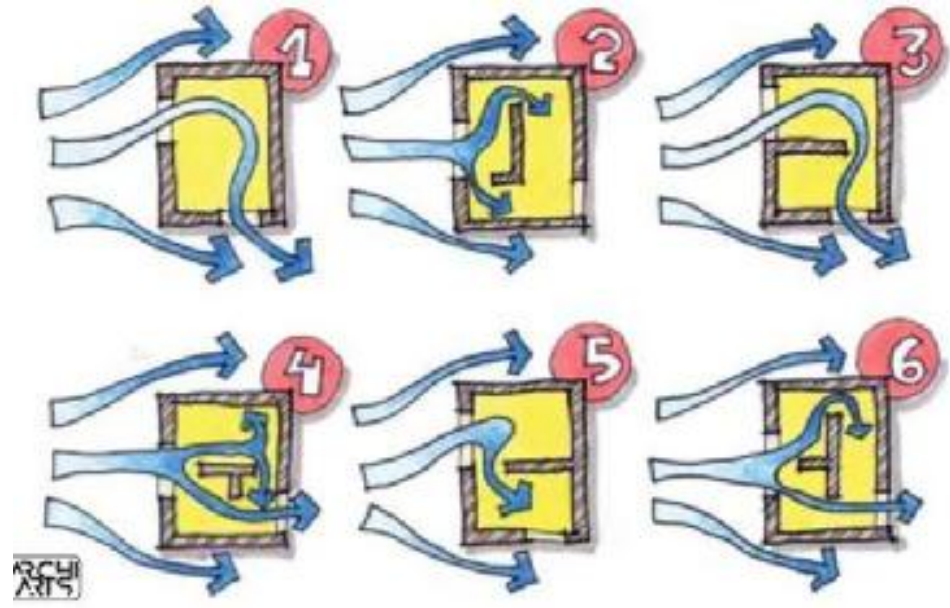

شكل رقم (†) الفتحات الخارجية وكيفية الاستفادة منها فى توزيع التهوية الطبيعية

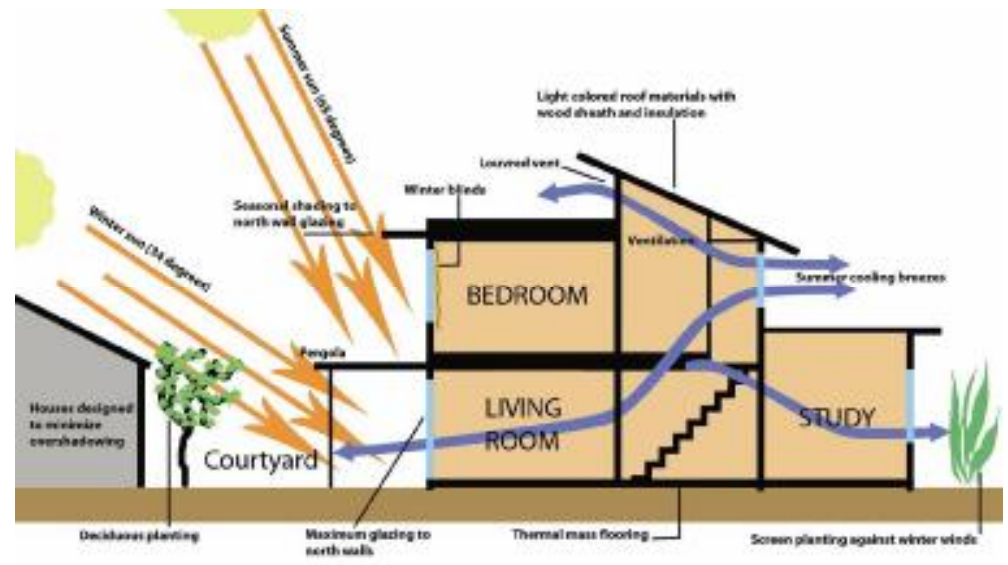

شكل رقم (V) يوضح بعض العناصر المعمارية فى المعالجات البيئية وهو" الفناء "

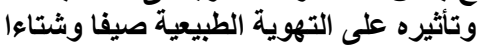




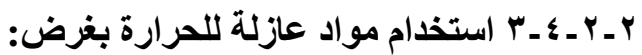

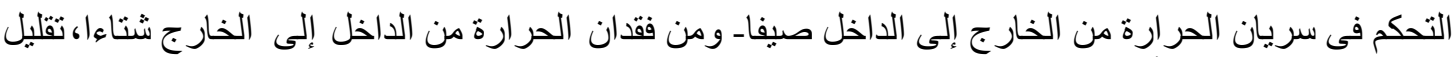

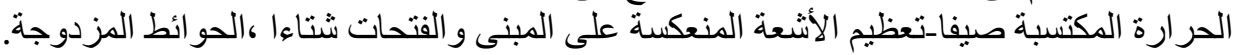

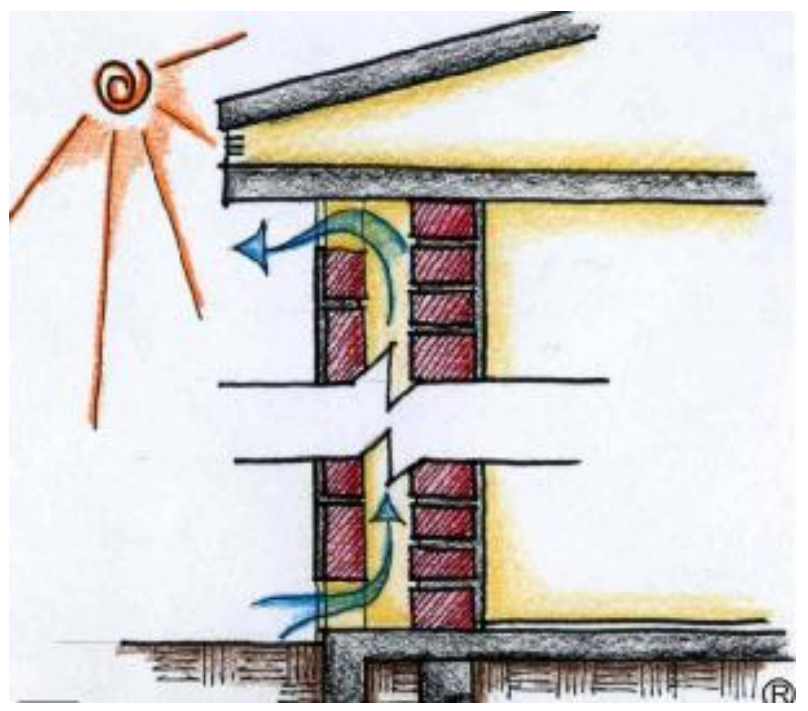

شكل (^) يوضح المواد العازلة مثال الحوائط المزدوجة للتقليل من درجة الحرارة بين داخل وخارج المبنى

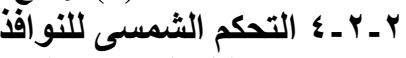

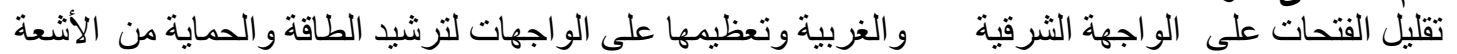

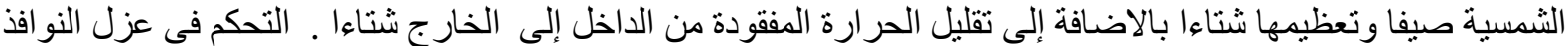
بغرض ترشيد الطاقة، استخدام الأرفف الضوئية، التظليل الداخلى للنو افذ، كاسر ات الثمس المتحركة والأفقية والرأسية

استخدام الطوام الحو ائطو المجمعات الثمسية بغرض تعظيم الحرارة المكتسبة شتاءا والاستفادة من الطاقة الثمسية

$$
\text { ب Y Y - Y الاستخدام السلبى للأشعة الشمسية }
$$

لتسخين المياه ونوليد الطاقة

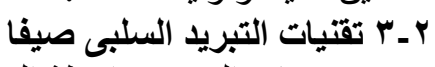

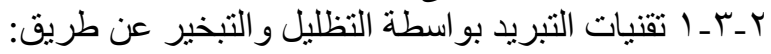
استخدام المزرو عات للغطاء النباتى ، استخدام رشاثنات المياه

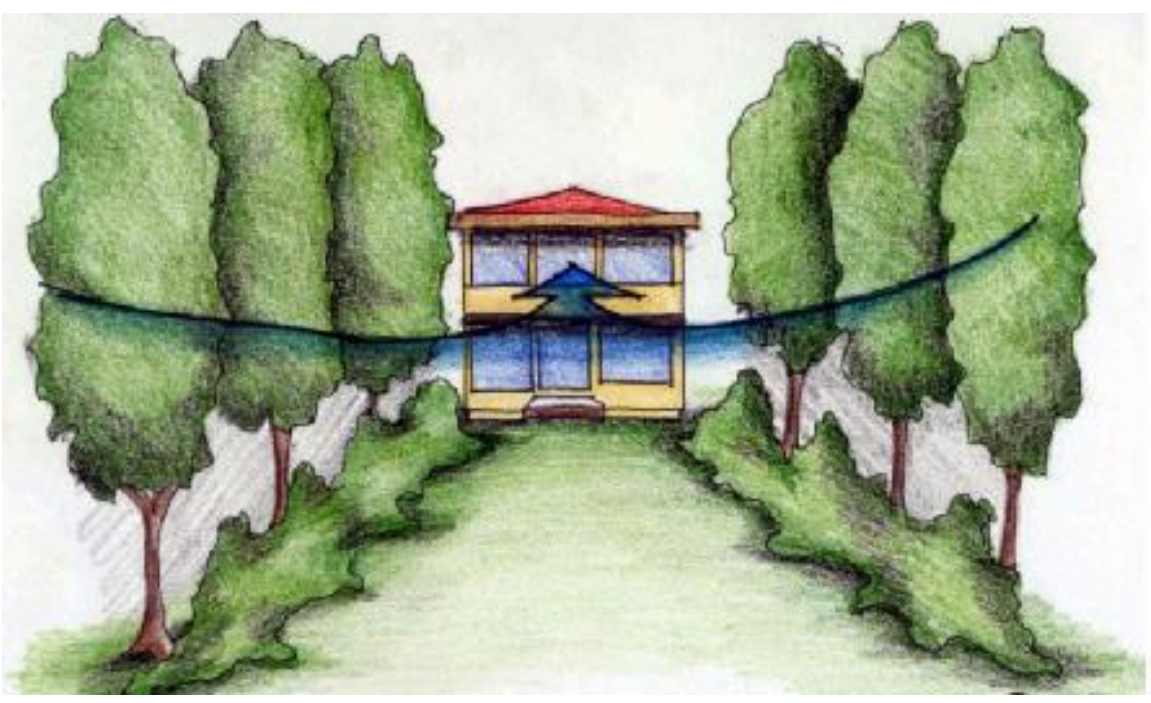

شكل(9) يوضح علاقة التثجير و التهوية الطبيعية والمداخل للتوجيه والتأكيد على أهمية المدخل

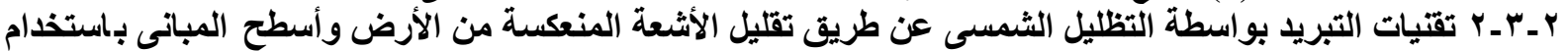

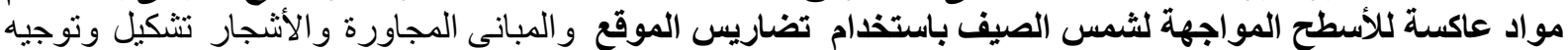

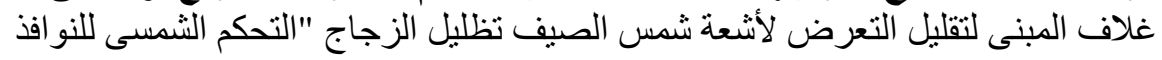




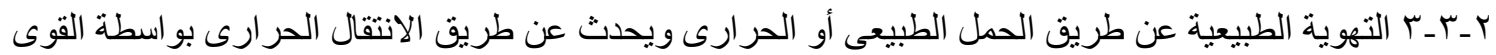

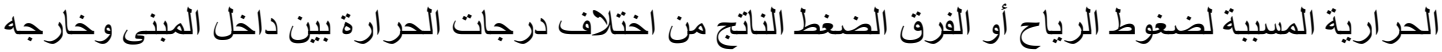

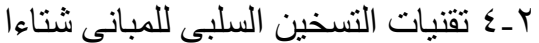

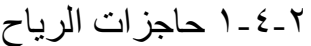
بـ ـ ـ ـ ـ ا استخدام طبو غر افيا الموقع و المزرو عات و المبانى المجاورة و الأشجار للحماية من الرياح الغير مستحبه وحجز

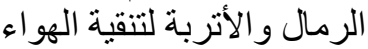

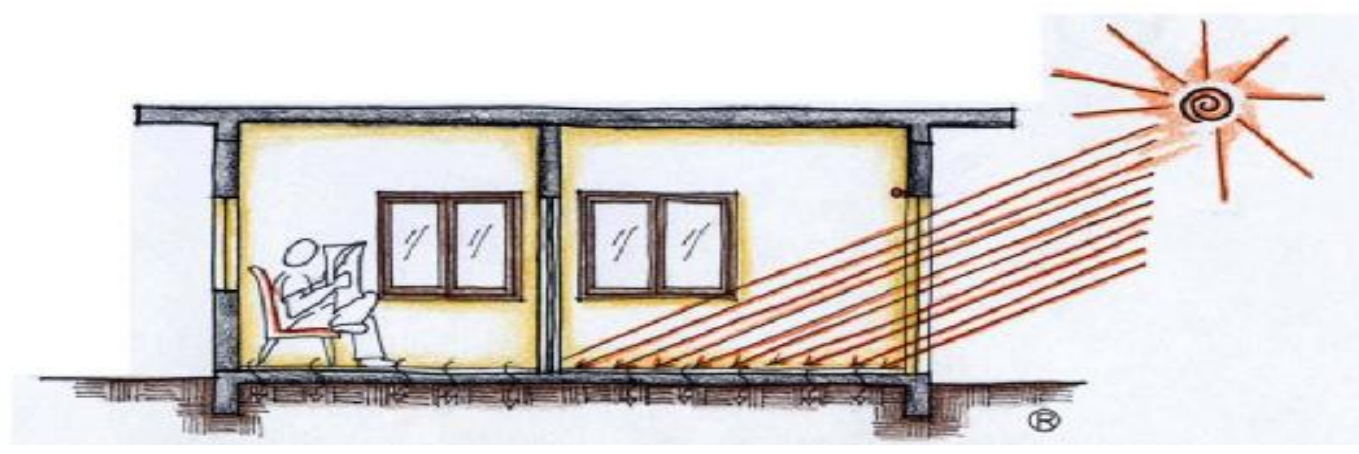

شكل (• (1) يوضح الإثعاع الثمسى للتدفئة خلال الثتاء وعلاقته بمسطحات الفتحات الخارجية

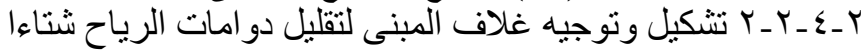

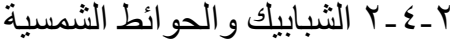

تعظيم الثبابيك الجنوبية و الأسطح العاكسة - استخدام الإضـاءة العلوية (الثخشيخة ) لاكتساب الطاقة الثمسية

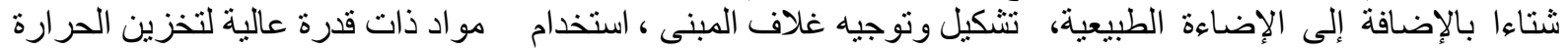

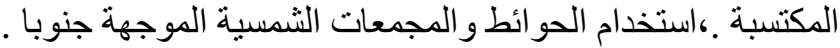

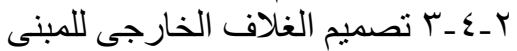

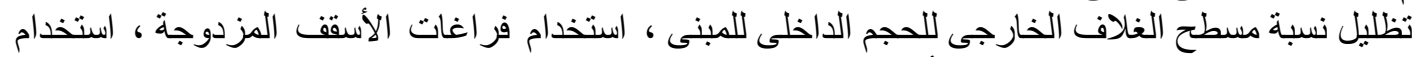

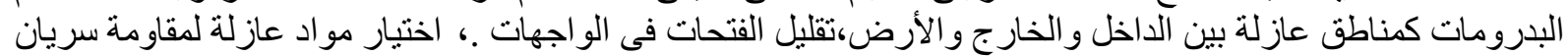

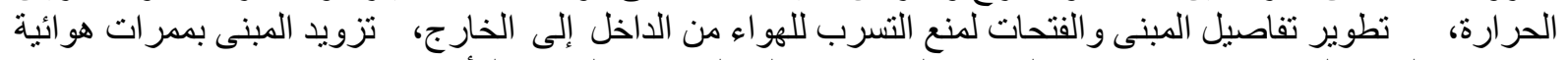
لاسترجاع الهو اء الساخن ، ممر ات تهوية لسريان الهو اءع من و الى الفر اغات الفئ الخاصة للأجهزة.

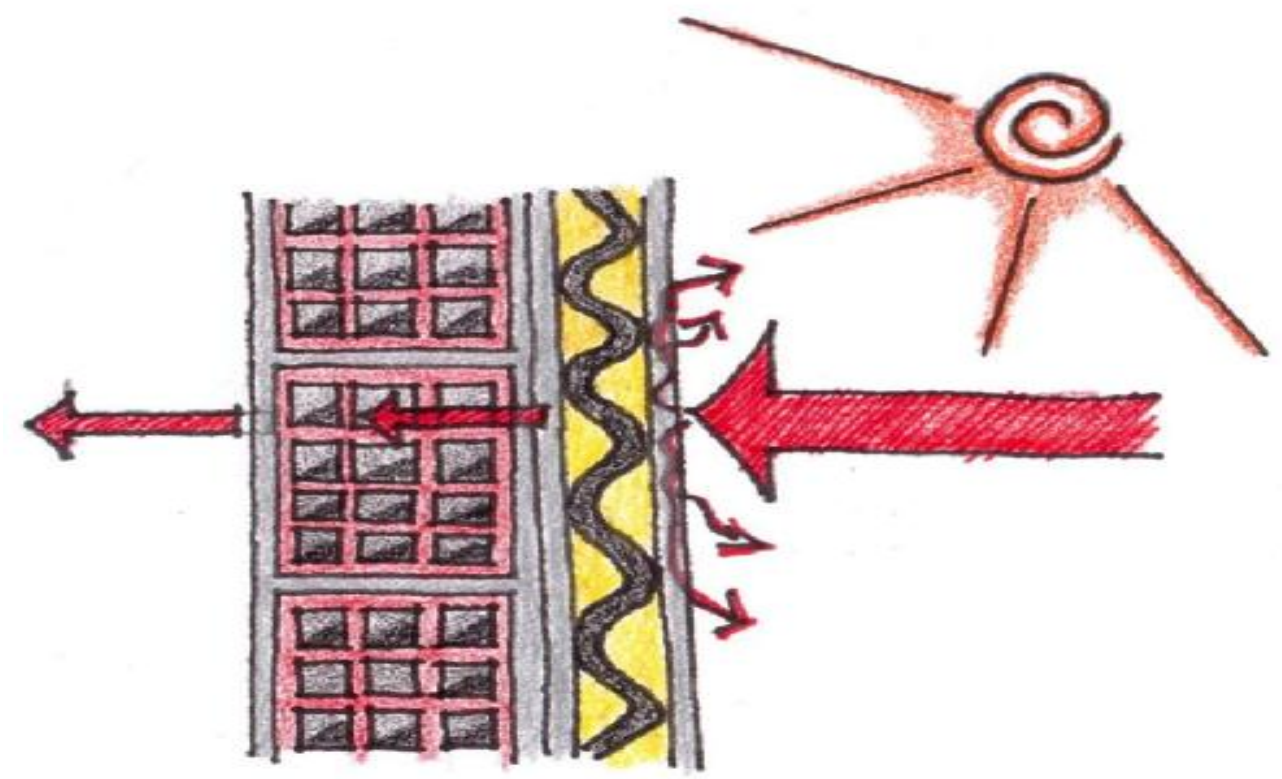

شكل يوضح (11) بعض المعالجات التقليدية للحوائط (سمك الحائط + الحائط المزدوج + الأسطح المنعكسة) لتقليل الانتقال الحرارى خلالها إلى داخل المبنى الطبل 

تزويد المبانى لمسطحات شبه محمية خارجية لتلطيف المناخ على مدار العام ، نوجيه الغرف و الفر اغات بحيث تتو افق مع

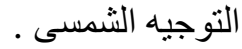
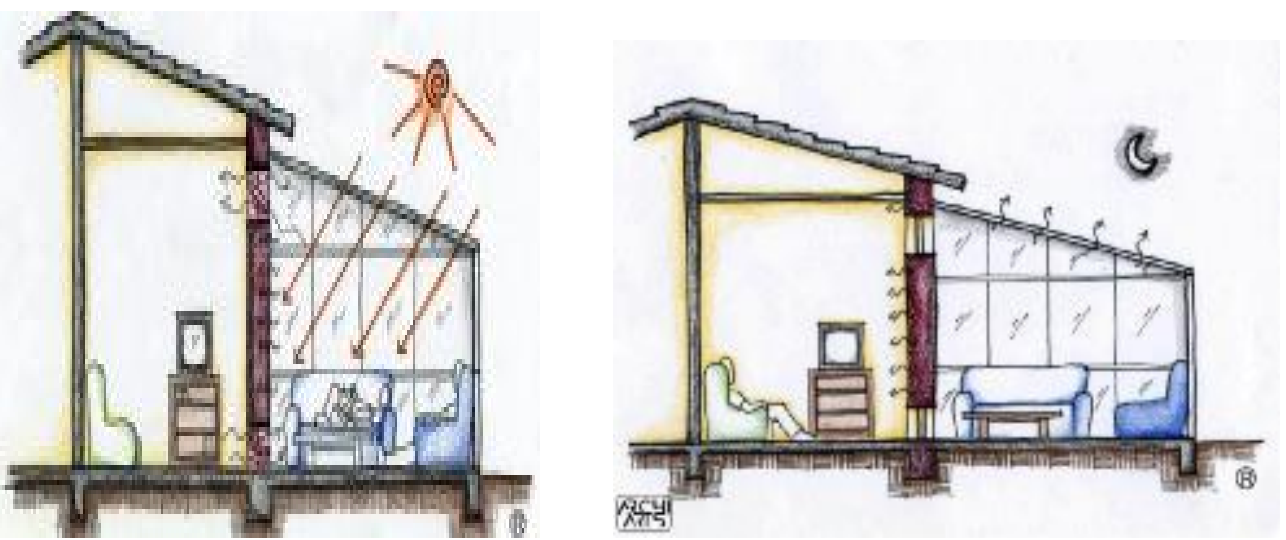

شكل (r ا ) يوضح "تخزين الطاقة الثمسية خلال النهار فى الثتاء للتدفئة و خلال الليل"

r البناء تحت الأرض أو رفع التربة أعلى سطح المبانى ـ استخدام الأسطح المزروعة فوق المبانى

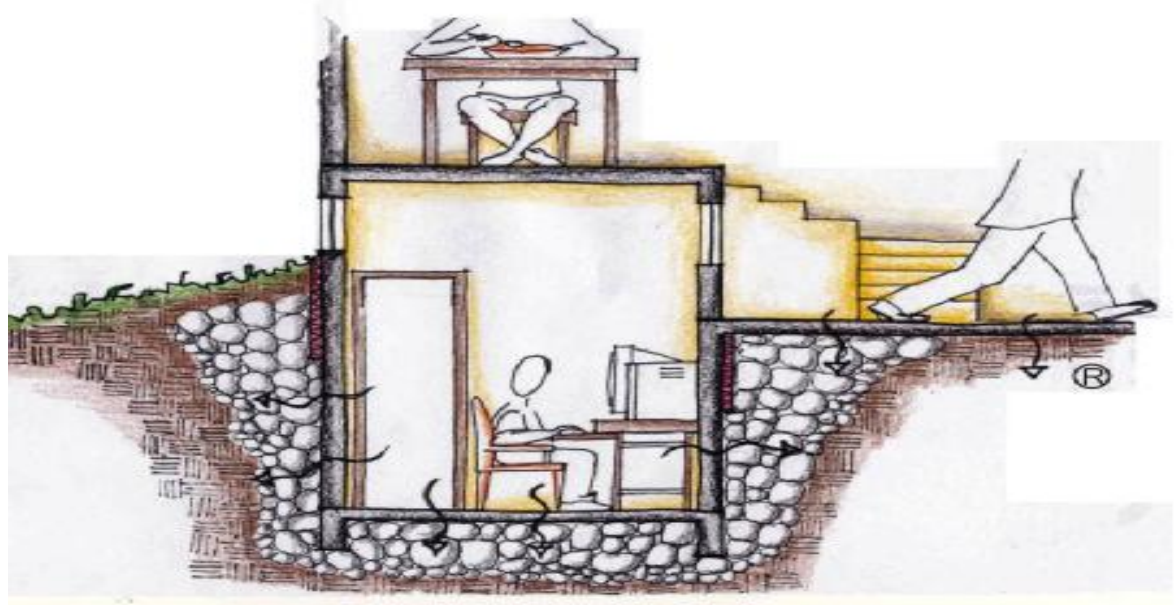

شكل (ب 1 ) يوضح البناء تحت الأرض وهو إحدى طرق المعالجات المناخية للحرارة

r ــ مواد البناء المتاحة فى مصر وترشيد الطاقة فى المبانى

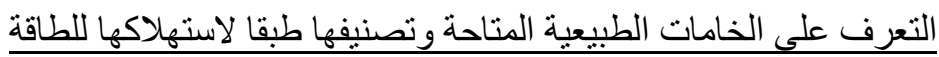

\begin{tabular}{|c|c|c|}
\hline مو اد قليلة الطاقة & مو اد متوسطة الطاقة & مو اد عالية الطاقة \\
\hline جول / طقن شدتها عن 0, · جيجا & 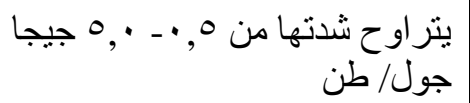 & جزيد استهلاكها للطاقة عن ه جيجا \\
\hline
\end{tabular}


وذللك عن طريق حساب كمية الطاقة اللازمة لإنتاج بعض مكونات المبانى من حو ائط و أسقق وأرضيات المخرجات.

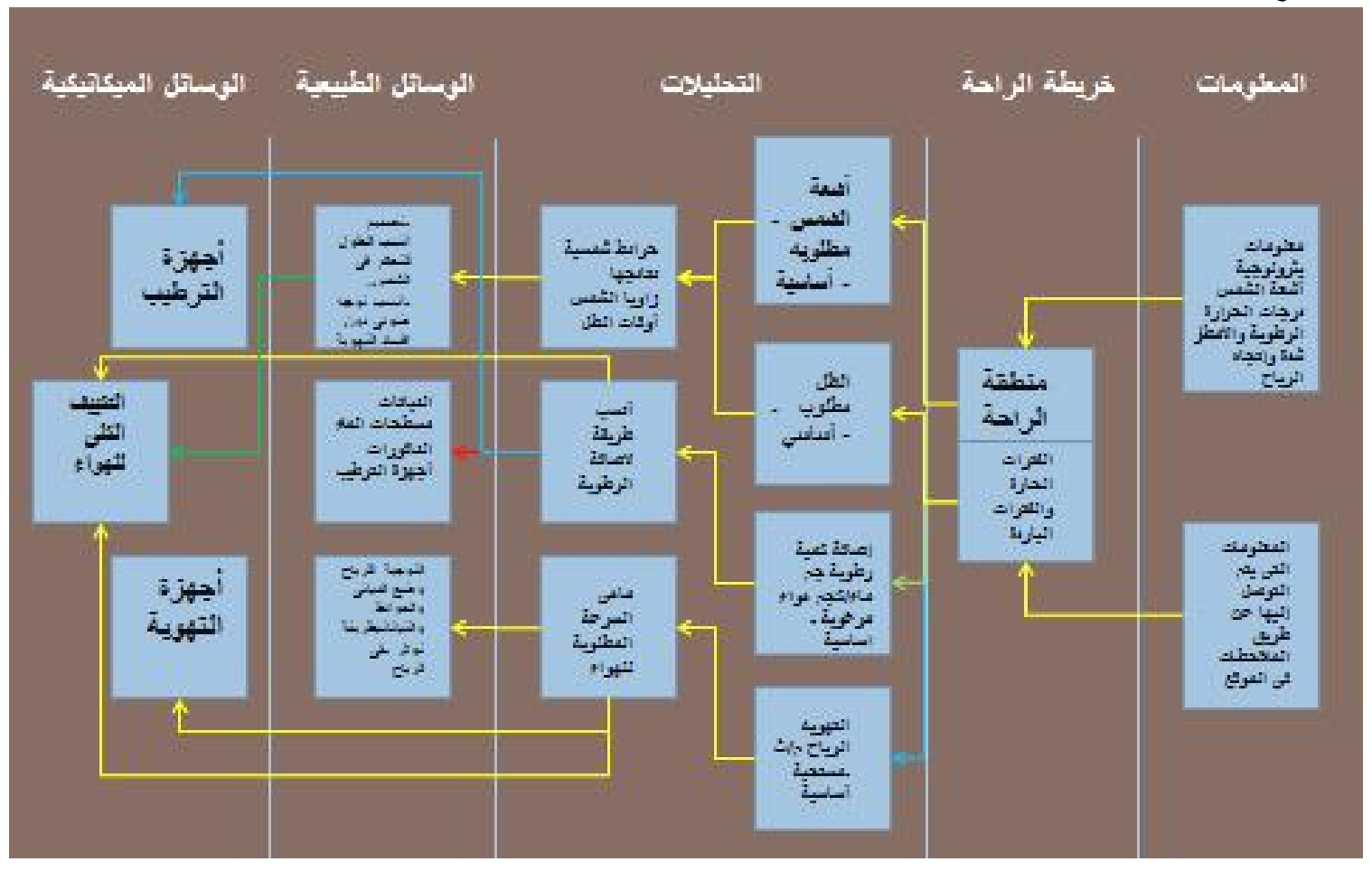

نماذج محلية وعالمية

المركز الفيدرالي الجنوبي (سياتل، واشنطن) بناء يوفز الطاقة و الهواء بشكل متجدد

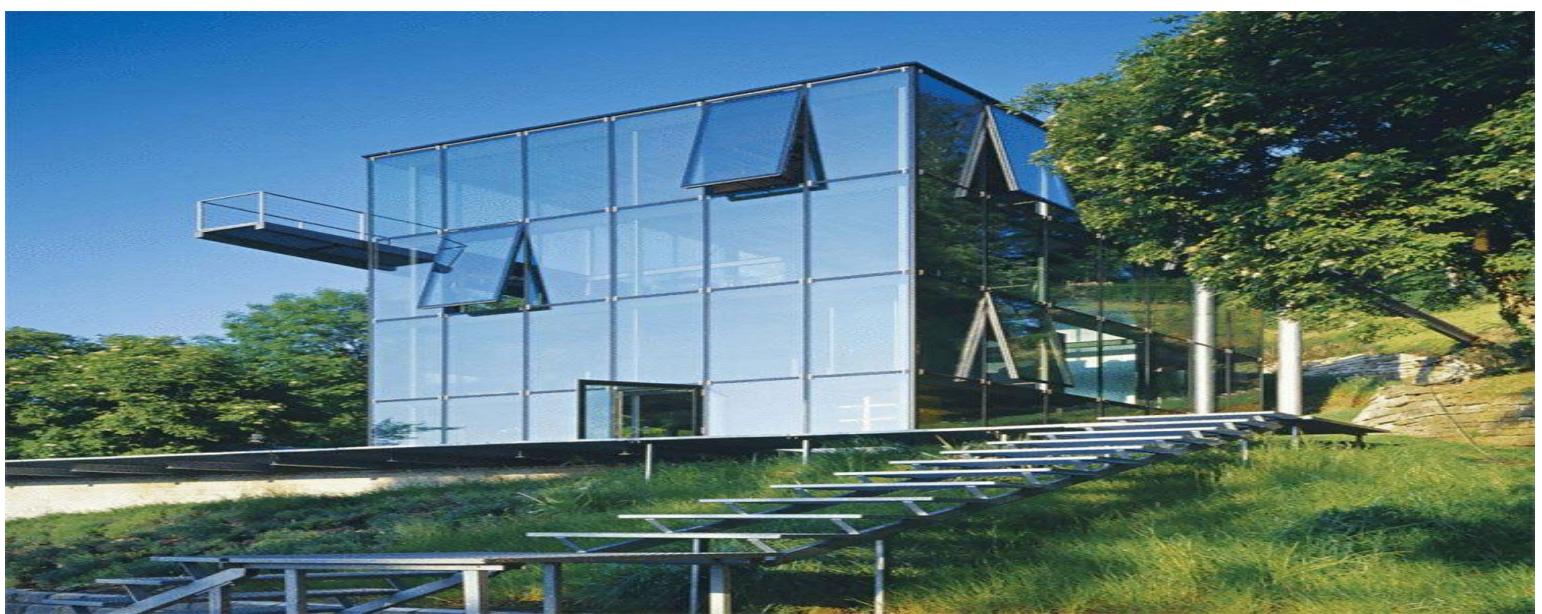

نموذجr شقق ديفيد تثارلز كيلينغ (سان دييغو، كاليفورنيا)

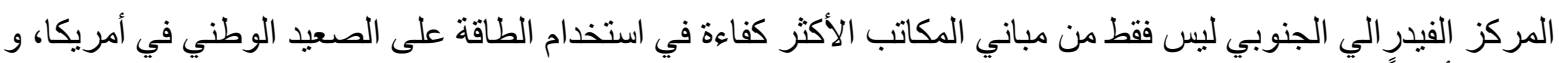

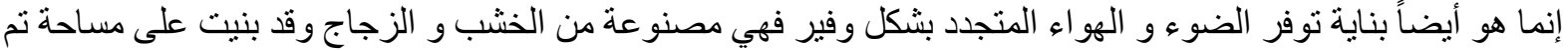

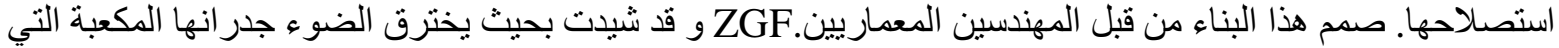

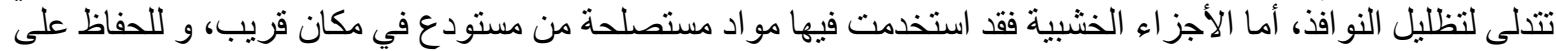
البرودة داخل البناية يمر الهو اء الخارجي عبر قنوات الترشيح ليتدفق من خلال الطو ابق. 


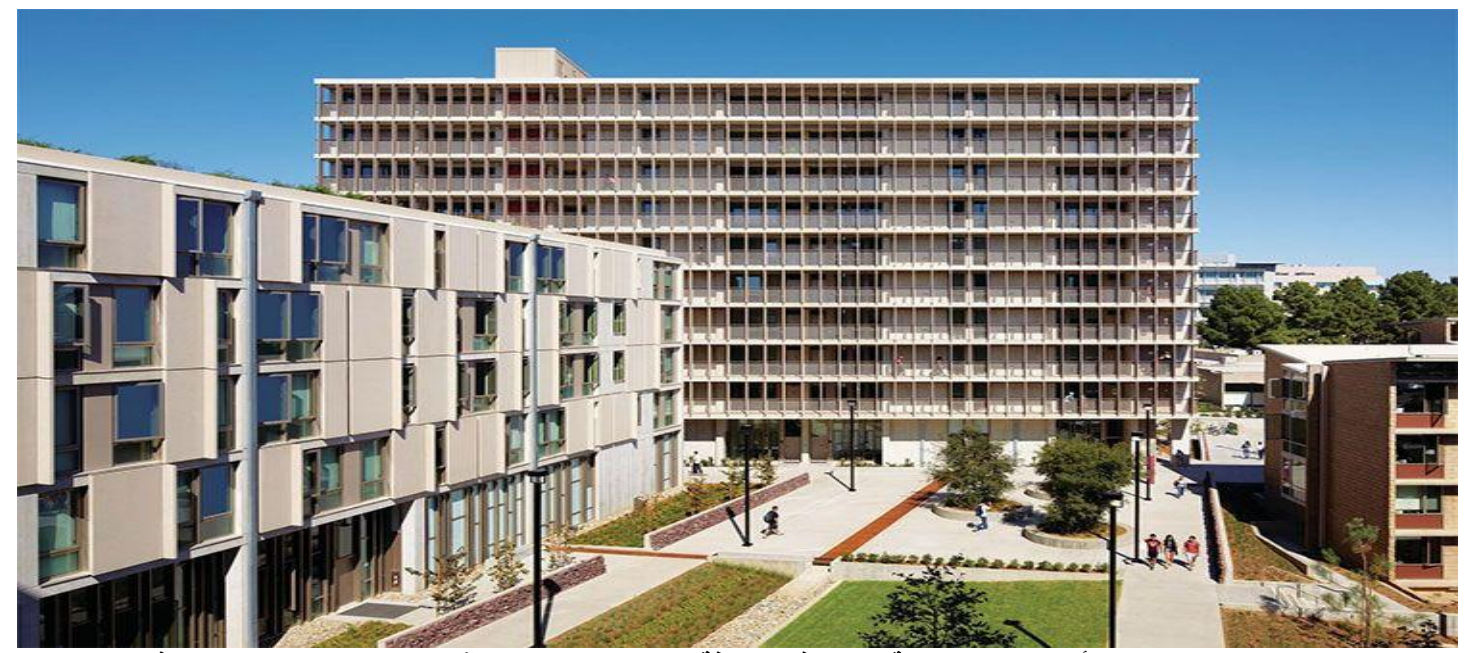

شقق تثارلز ديفيد كيلينغ التي تتميز بأثكالها المستقيمة وزخارفها إضافة إلى كونها من المنثآت الخضراء، حيث استخذم فيها الزجاج بثكل

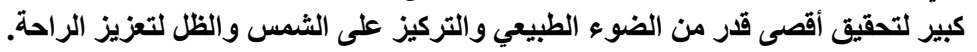

الحرم الجامعي في جامعة سان دييغو في ولاية كاليفورنيا ليس غريبا على الهندسة المعمارية اللافتة للنظر ، فاللى جانب

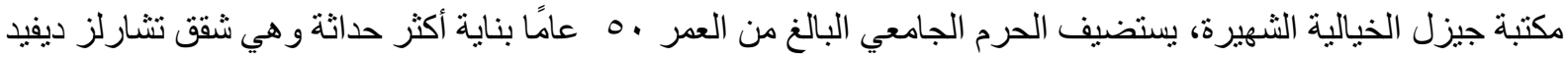

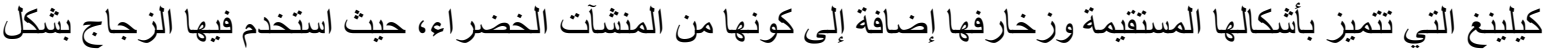

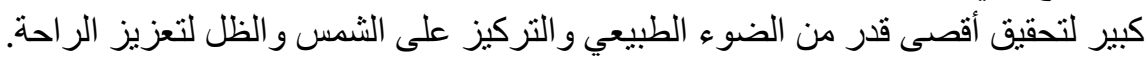

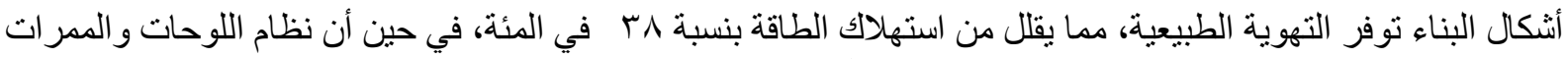

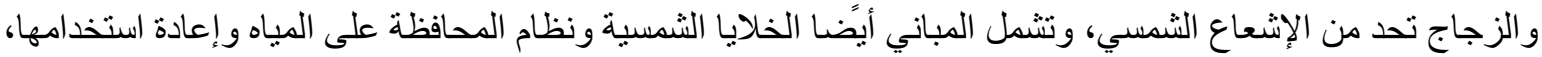

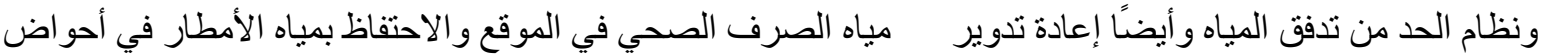

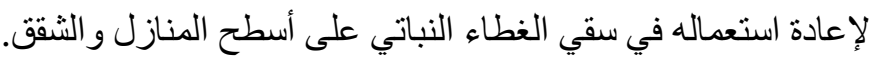

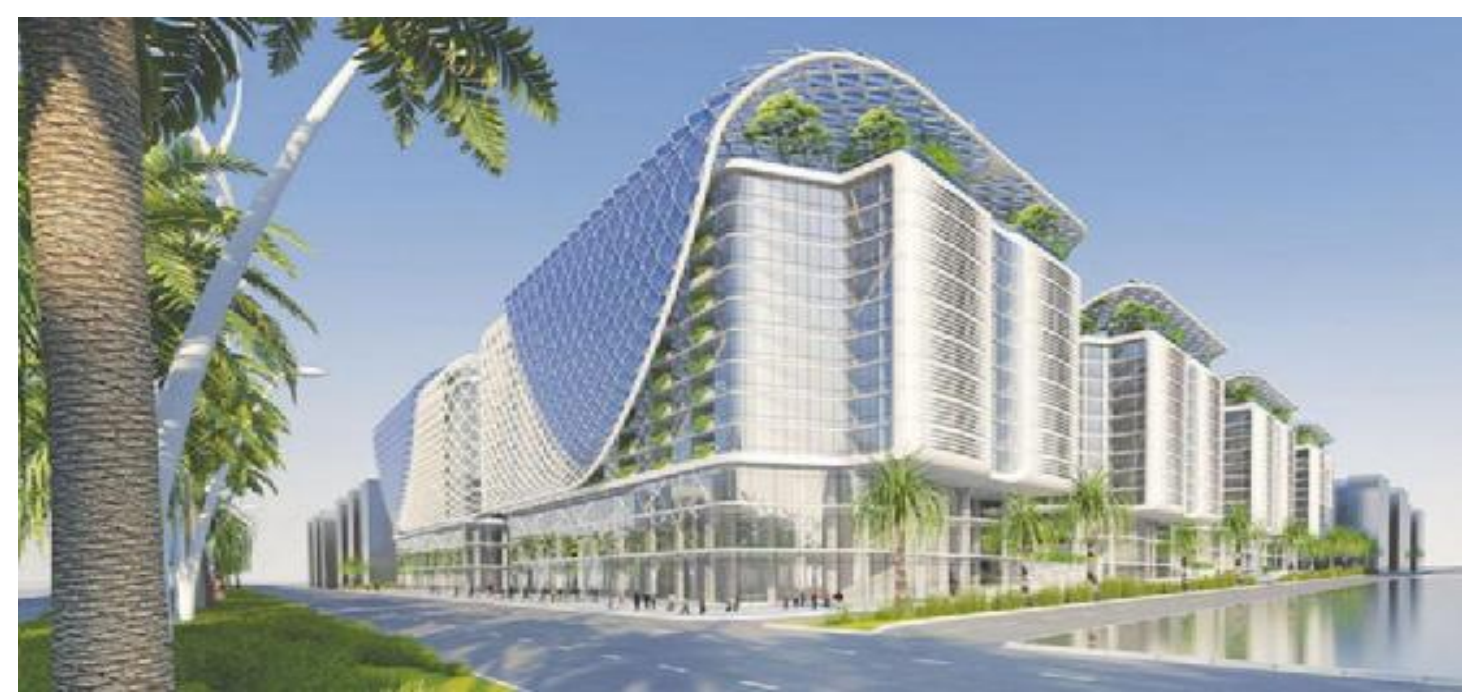

فعلى أطر اف شمال شرقي القاهرة، يقع حي هليوبوليس، الذئي يعتبر واجهة العاصمة من الجهة الثرقية، و أحد مداخلها

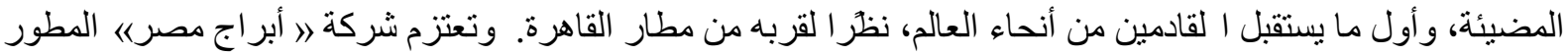

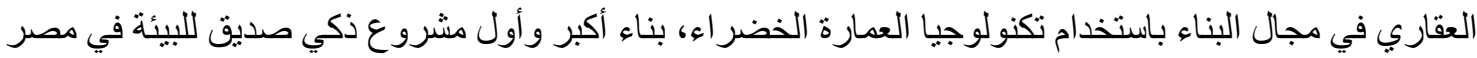
و الثرق الأوسط، فضلاً عن الثقق الفندقية Element by Westin، والمشاريع الصديقة للبيئة تستخدم تكنولو جيا العمارة الخضر اء، التي تراعي المعايير البيئية وتستخدم الكهرباء النظيفة، وتقلل من الإشعاعات الناتجة من الثبكات اللاسلكية، 


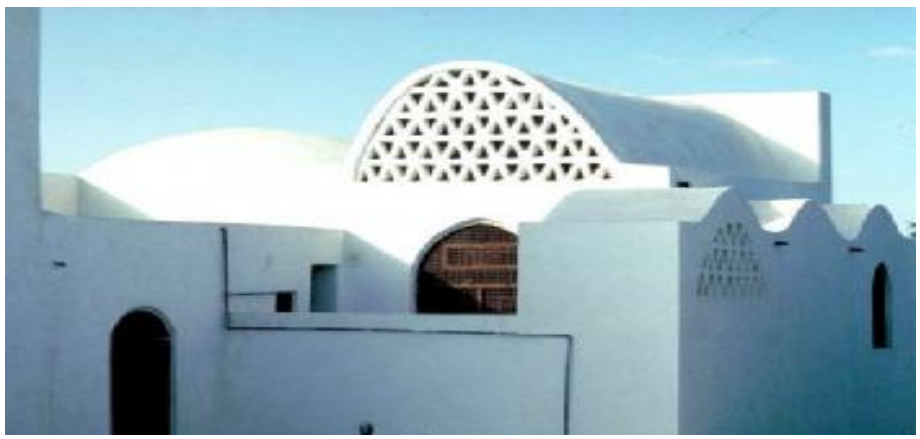

نموذج للمعمارى المصرى حسن فتحى منزل سامى عقيل - دهشور(مصر )

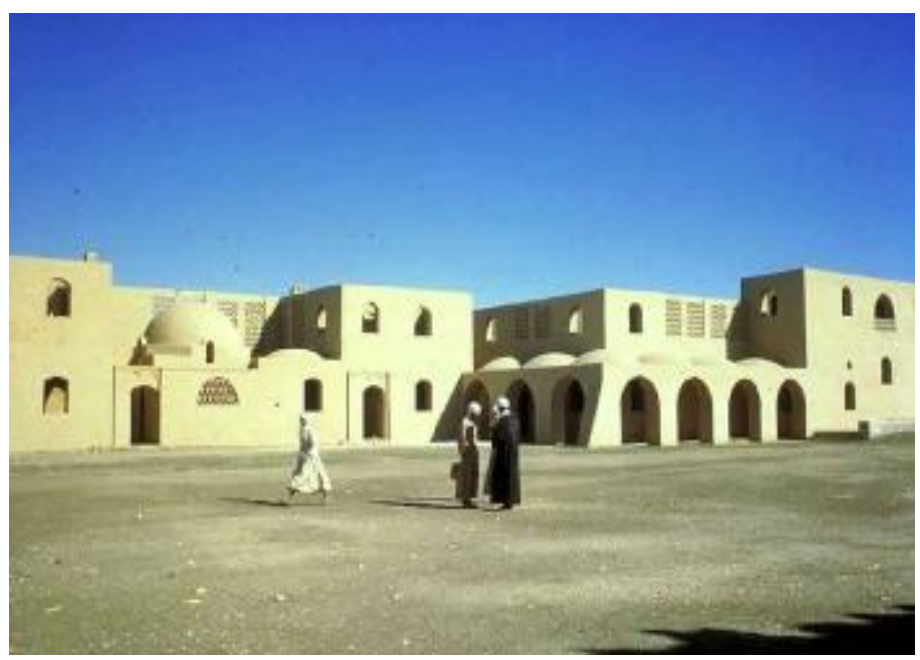

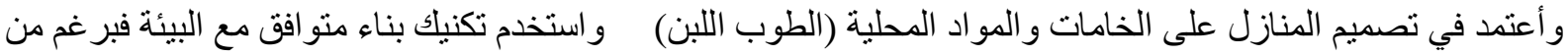

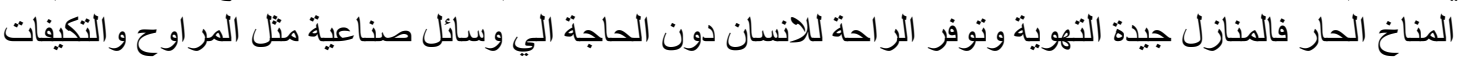

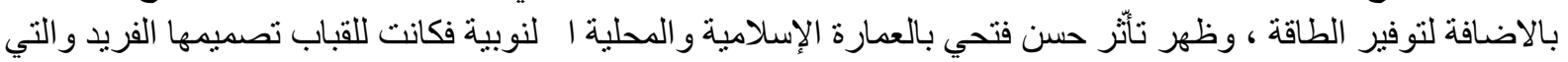
أستخدمت بدلا من الأسقف التي تعتمد على الألواح الخشبية أو الخرسانة المسلحة

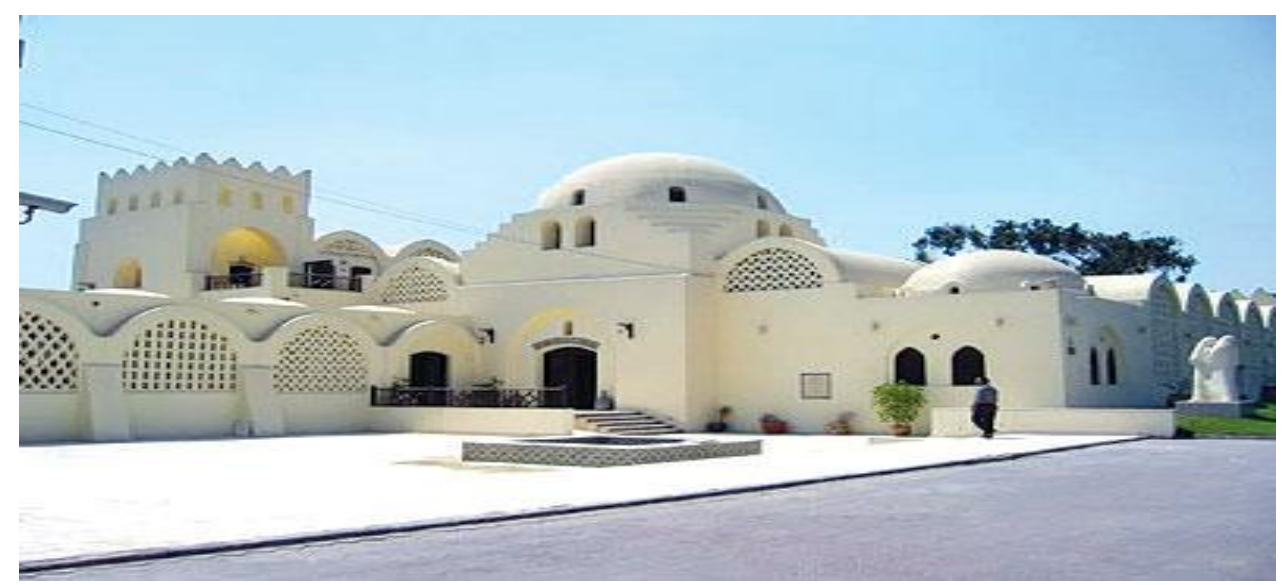

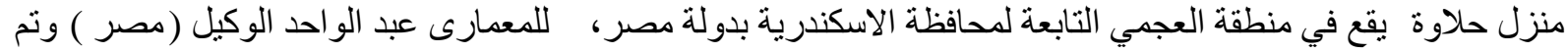
استفادة من الاساليب المعمارية المحلية مثل الافنية الداخلية لتوفير الخصوصية وتبريد الهو اءهية واستخدام مواد محلية متوفرة.

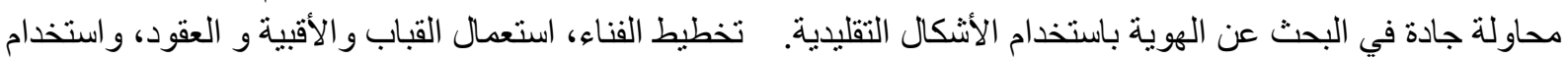
مو اد محلية، نوفير المساحات و الإستخدام الأمثل للضوء من من أجل بناء منزل بستوفي منطلبات العصدر. 


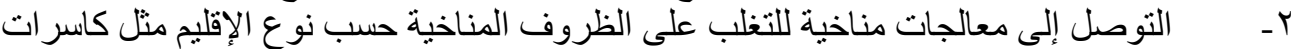

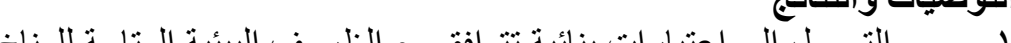

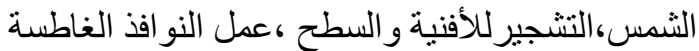

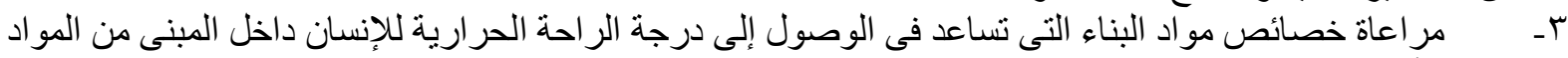

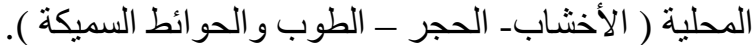

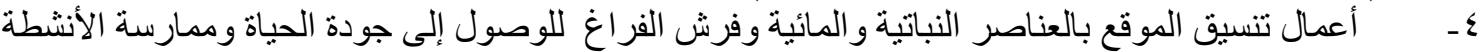
الاجتماعية فى الفر اغات العمر انية.

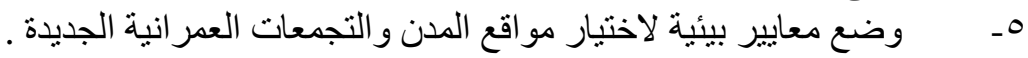

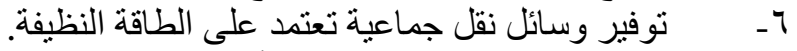

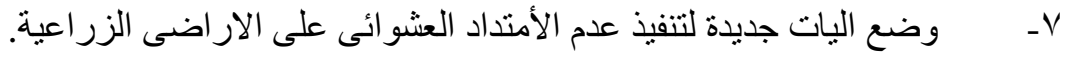

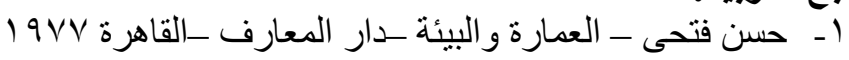

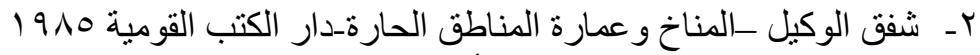

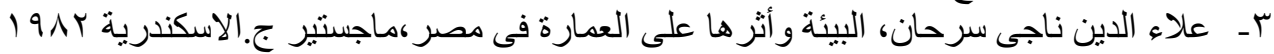

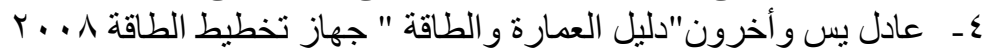

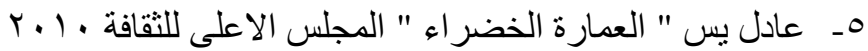

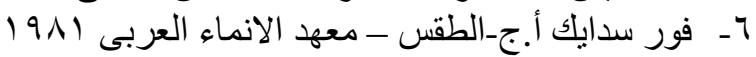

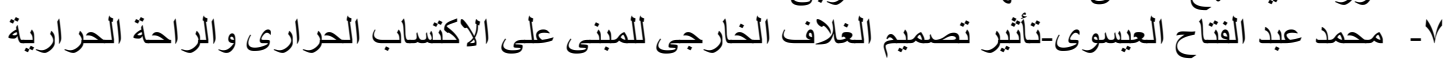

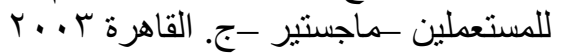

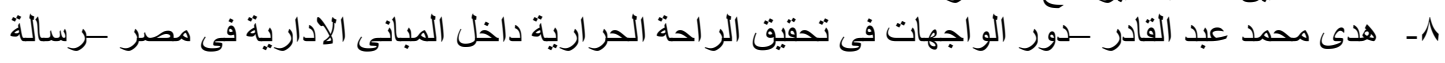

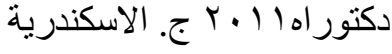

